\title{
REDUÇÃO DE CUSTOS SOB A ÓTICA DA MANUFATURA ENXUTA EM EMPRESA DE AUTOPEÇAS
}

\section{COST SAVINGS FROM THE PERSPECTIVE OF LEAN MANUFACTURING IN COMPANY OF AUTO PARTS}

\author{
Ana Cristina de Faria ${ }^{1}$; Vanessa Simões Vieira ${ }^{2}$; Luiz Celso Peretti ${ }^{3}$ \\ ${ }^{1}$ Universidade Municipal de São Caetano do Sul - USCS - São Paulo - Brasil \\ anacfaria@uol.com.br \\ ${ }^{2}$ Universidade Municipal de São Caetano do Sul - USCS - São Paulo - Brasil \\ vanessavieira@mmcb.com.br \\ ${ }^{3}$ Universidade Municipal de São Caetano do Sul - USCS - São Paulo - Brasil \\ luizcelsoperetti@gmail.com
}

\begin{abstract}
Resumo
O objetivo deste artigo é investigar, por meio de estudo de caso, a perda nas operações com movimentações, em uma célula de trabalho, que não agregam valor, bem como buscar alternativas para minimizar essas perdas por meio de ferramentas para alcançar reduções de custos. Desenvolveu-se a pesquisa em empresa de autopeças, de acordo com a metodologia de World Class Manufaturing de Yamashina (2000), focando na redução de perdas, desperdícios e, consequentemente custos. Utilizou-se o método kaizen, as ferramentas da qualidade $5 \mathrm{W1H}$, os $5 S^{\prime}$ 's, VSM, Diagrama de Causa e Efeito, Ciclo PDCA e a Matriz de perdas. Houve a mudança no layout, além de mudança de processo, máquinas, transporte, entrega e gestão dos materiais. Com isso, a produtividade aumentou, o tempo de ciclo diminuiu, foram diminuídos dois operários por turno, reduzindo o custo com mão-de-obra direta. Houve benefícios econômico-financeiros de $R \$$ 50.634,00, além de proporcionar o balanceamento da linha; o aumento produtividade; a redução de atividades que não agregam valor (transporte e movimentação), a motivação dos operadores por meio das sugestões de melhorias e a organização e limpeza do posto de trabalho. $O$ custo total do projeto foi de $R \$ R \$ 6.359,00$, obtendo-se uma economia total (saving) de $R \$ 44.275,00$. Com as melhorias e redução de perdas e desperdícios, a empresa pode diminuir seu preço de venda, tornando-se mais competitiva no mercado, além de melhorar a qualidade dos produtos e as condições de seus funcionários, diminuir o tempo de entrega e cumprindo com os prazos negociados com os clientes.
\end{abstract}

Palavras-chave: desperdícios; kaizen; manufatura enxuta; perdas; produtividade.

\section{Introdução}

Com clientes cada vez mais exigentes no que se refere à inovação, à entrega, à qualidade, aos prazos e, principalmente, aos preços dos produtos e serviços, as empresas precisam ter flexibilidade em sua produção e buscar, continuamente, o aumento da produtividade, eficiência e 
melhoria contínua de seus produtos e serviços, em meio a um mercado cada dia mais competitivo, em meio à concorrência.

E nesse ambiente, podem existem perdas normais, que são inerentes ao processo produtivo. Quanto maior são essas perdas, menos eficiente é o processo analisado. É fundamental que as atividades do processo produtivo que não agregam valor ao produto sejam sistematicamente reduzidas e as perdas eliminadas (BORNIA, 1995). Conforme Shingo (1996b), a função processo consiste de processamento, inspeção, transporte e estocagem; porém, apenas o processamento agrega valor. Isso todos sabem bem na Toyota Motor Company, onde a meta é a redução de custo por meio da eliminação das perdas, especialmente a por superprodução. A inspeção, o transporte e, especialmente, a estocagem, ou a prática de manter estoque, podem ser considerados desperdícios, se mal administrados, e eliminados sempre que isso for possível.

Os desperdícios nos movimentos correspondem às ações consideradas inúteis ao processo e que são realizadas em linhas fabricação e máquinas. Diante disso, os gestores devem delegar ao operador o máximo de atividades relativas ao produto, eliminando todo e qualquer movimento desnecessário. A maioria dos processos apresenta $90 \%$ de perdas e $10 \%$ de trabalho com agregação de valor (LIKER, 2006).

Quando o aumento da oferta de produtos supera o crescimento da demanda, a competição entre as empresas intensifica-se e o preço de venda dos produtos sofre redução contínua. Com preços de venda mais baixos, para não diminuir sua margem de lucro, as empresas são forçadas a buscar a redução de custos (BORNIA, 1995).

Shingo (1996a) afirma que a redução de custos só é possível por meio da eliminação de perdas - ineficiências e desperdícios. Para Monden (1999), a otimização do arranjo físico possibilita a eliminação de inúmeras perdas, devido à movimentação e transporte de materiais, estimula o trabalho em equipe e facilita a resposta no que tange à qualidade, resultando em melhores índices de qualidade e produtividade. Diante desse contexto, o problema que norteia esta pesquisa é:

Como reduzir os custos de mão-de-obra direta em uma empresa de autopeças e tornar a produtividade mais enxuta?

Para responder a esta questão, o objetivo deste trabalho é investigar, por meio de estudo de caso, a perda nas operações com movimentações, em uma célula de trabalho, que não agregam valor, bem como buscar alternativas para minimizar essas perdas por meio de ferramentas para alcançar reduções de custos.

No intuito de atingir o objetivo supracitado, este trabalho está estruturado da seguinte forma: no próximo tópico será comentado sobre a Manufatura Enxuta e Perdas e Desperdícios, incuindo o Sistema Toyota de Produção. Posteriormente, serão abordados o Custeio Kaizen, a filosofia dos 5S e VSM (Visual Stream Mapping), Cinco Porquês - 5W1H, o Diagrama de Causa e Efeito e o Ciclo 
PDCA. No terceiro tópico, será feita uma descrição dos aspectos metodológicos da pesquisa. No quarto tópico será desenvolvido o Estudo de Caso em uma empresa de autopeças, e posteriormente, serão evidenciadas as conclusões e recomendações gerais.

\section{Fundamentação teórica}

Neste tópico, será desenvolvida fundamentação teórica deste trabalho.

\subsection{Manufatura Enxuta}

A Manufatura Enxuta (Lean Manufacturing) teve início na década de 1950, no Japão, mais especificamente na montadora Toyota; por isso também é conhecida como Sistema Toyota de Produção. De acordo com Womack; Jones; Ross (2004), o Sistema Toyota de Produção surgiu quando Eiiji Toyoda e Taiichi Ohno, da referida empresa, perceberam que a manufatura em massa não funcionaria no Japão, então adotaram uma nova abordagem para a produção, com o objetivo de eliminação de desperdícios, e a necessidade do enfrentamento à nova concorrencia mundial. Para isso, utilizavam o paradigma na produção em grande variações de pequenos lotes, redução de setup, redução de estoques, alto foco na qualidade e outras alternativas.

O foco da Manufatura Enxuta é a eliminação de perdas e desperdícios em processos produtivos, por meio da melhoria contínua dos processos e foco nos clientes. Com tais princípios, essa filosofia vem demonstrando ser uma poderosa ferramenta estratégica. Rother e Shook (1999) definem que Manufatura Enxuta é o conjunto das melhores práticas que cruzam as fronteiras departamentais com o objetivo de eliminar desperdício e criar valor. Conforme Ahlström e Karlsson (1996), a Manufatura Enxuta consiste na demonstração dos seguintes princípios: Eliminação de desperdícios; Melhoria Contínua; Zero Defeitos/Just in Time-JIT; Mudança do sistema Push para Pull; Equipes Multifuncionais e Responsabilidades Descentralizadas com Funções Integradas e Sistemas de Informações Horizontais e Verticais.

A estratégia de Manufatura Enxuta abrange os conceitos criados, principalmente pelas empresas japonesas (TPS) a partir da década de 60, como Just-in-time, Total Quality Management, (TQM), melhoria contínua (kaizen), controle estatístico de processo, engenharia simultânea e produção enxuta (SCHONBERGER, 1986; CLARCK, 1996).

Na visão de Shah e Ward (2003), o ponto fundamental dessa filosofia é a criação de um sistema de alta qualidade que fabrica produtos no ritmo em que o cliente deseja sem desperdícios. Tem sido aplicada em várias empresas industriais, com o objetivo de torná-las mais lucrativas. Para isso, cada pessoa da organização tem papel chave durante o processo de melhoria (SHINGO, 1996a). Este autor afirma que o Sistema Toyota de Produção (TPS) apresenta as seguintes características principais: (i) a minimização de custos por meio da eliminação total de desperdícios 
como princípio fundamental para a sobrevivência da empresa; (ii) a produção contrapedido, por meio da eliminação da superprodução e da redução dos tamanhos dos lotes, como a melhor forma de atender à demanda; (iii) o método Kanban para controlar o processo e alcançar flexibilidade; (iv) a utilização de máquinas independentes de trabalhadores para reduzir o custo de mão-de-obra e (v) a queda de crenças comumente aceitas por meio da investigação das origens da produção convencional.

Conforme Solomon e Fullerton (2007), a World Class Manufacturing é, em síntese, a busca da excelência pela aplicação das metodologias e ferramentas fundamentadas na Manufatura Enxuta, que por sua vez é baseada no TPS. Esse novo paradigma, chamado de World Class Manufacturing, (WCM) ou manufatura de classe mundial, é baseado na análise das práticas implementadas por empresas japonesas, americanas e alemãs, que apresentavam um grande rendimento notável em suas indústrias (HAYES; WHEELWRIGHT, 1984; SCHONBERGER, 1986; HAYES; PISANO, 1996).

As características principais do TPS citadas por Shingo (1996a) podem ser mais bem compreendidas pela descrição dos pilares e princípios básicos do sistema. Shingo (1996a; 1996b) diferencia processos de operações da seguinte forma: Processo é o fluxo de material no tempo e no espaço; diz respeito aos estágios da matéria-prima até o produto acabado, no fluxo de um trabalhador para o outro, e Operação refere-se ao fluxo do trabalho realizado para efetivar as transformações do material; é o estágio em que um trabalhador ou uma máquina executa um trabalho sobre os materiais e pode lidar com diferentes produtos. A Figura 1, a seguir, apresenta a estrutura da produção em rede proposta por Shingo, com os processos ocorrendo na direção vertical e as operações ocorrendo na direção horizontal:

Figura 1: A estrutura da produção

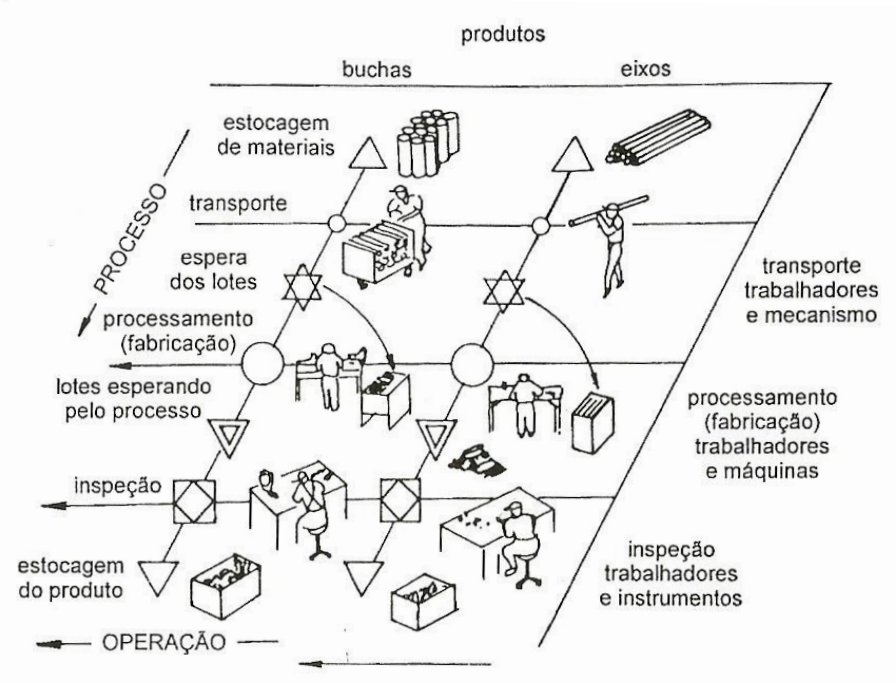

Fonte: Shingo (1996a, p. 38) 
O processo de planejamento de layout, baseado na Manufatura Enxuta, tem como vantagem direta a redução dos custos de produção, por meio da eliminação de perdas. Com a estratégia de Manufatura Enxuta, procurou-se ouvir as pessoas e utilizou-se o conhecimento delas no processo a ser repensado para refletir as melhorias (DRUCKER, 1992, p. 111).

\subsection{Perdas e Desperdícios}

Para Brinson (1996, p.80), perdas e desperdícios são constituídas pelas atividades que não agregam valor e que resultam em gastos de tempo, dinheiro, recursos sem lucro, além de adicionarem custos desnecessários aos produtos. Atividades que não agregam valor (NVAA) são as que podem ser eliminadas sem que haja deterioração no desempenho da empresa (custo, funcionalidade, qualidade e valor agregado). Nessa mesma linha, Nakagawa (1993, p.19) atribui como desperdício todas as formas de custos que não adicionam qualquer valor ao produto, sob a ótica do consumidor. Desperdício, no entender de Robles Jr. (2003, p.17), é a perda a que a sociedade é submetida devido ao uso de recursos escassos. Esses recursos escassos vão desde material, mão-de-obra e energia perdidos, até a perda de horas de treinamento e aprendizado que a empresa e a sociedade perdem, devido, por exemplo, a um acidente de trabalho. Conforme Liker (2006, p. 47), a Toyota identificou sete grandes perdas sem agregação de valor em processos administrativos ou de produção, os quais estão descritos a seguir:

Superprodução - Liker (2006, p. 47) comenta que envolve a produção de itens para os quais não há demanda, o que gera perda com excesso e de estoque e com os custos de transporte devido ao estoque excessivo - ocorre quando a empresa produz em quantidade maior que a necessária ou antecipadamente (antes do momento necessário). Dessa forma, gera-se excesso de inventário (SHINGO, 1996a). Na visão de Ohno (1997), a perda por superprodução é a mais crítica, pois esconde outros desperdícios. Bornia (1995) afirma que para eliminar este tipo de perda é necessário promover melhorias nos processos, de modo a conseguir um fluxo contínuo de materiais e redução nos tempos de preparação de equipamentos, visando a permitir a produção de lotes menores.

Espera (tempo sem trabalho) - Conforme Liker (2006, p. 47), são os funcionários que servem apenas para vigiar uma máquina automática ou que ficam, esperando pelo próximo passo no processamento, ferramenta, suprimento e peças. As esperas podem ser necessárias ou desnecessárias à estabilização de um processo e podem ser causadas por capacidade excedente ou pela programação de produção (SHINGO, 1996b). Para minimizar as esperas nos processos, é necessário reduzir tempos de preparação de máquinas, balancear a produção e melhorar a confiabilidade do sistema para reduzir falhas não previstas (BORNIA, 1995). 
Transporte ou movimentação desnecessária - Segundo Liker (2006, p. 47), é o movimento de estoque em processo por longas distâncias, criação de transporte ineficiente ou movimentação de materiais, peças ou produtos acabados para dentro e fora do estoque e entre processos. A redução da perda com transporte depende da reorganização do espaço físico da fábrica e deve-se buscar minimizar ou eliminar necessidades de movimentação de materiais por meio de modificações no layout. Quando esgotadas as possibilidades de melhoria do processo, a atenção pode voltar-se para a melhoria das operações, como aplicação de esteiras rolantes, braços mecânicos etc. (BORNIA, 1995; SHINGO, 1996a; 1996b).

Superprocessamento ou processamento incorreto - é o processamento ineficiente devido a uma ferramenta ou ao projeto de baixa qualidade do produto, causando movimento desnecessário e produzindo defeitos (LIKER, 2006, p. 47). Para localizar este tipo de perda, Shingo (1996a, p. 41) propõe que sejam feitos os seguintes questionamentos: "Como este produto pode ser redesenhado para manter a qualidade e, ao mesmo tempo, reduzir custos?" "Como a fabricação deste produto pode ser melhorada?".

Na visão de Shingo (1996a), o primeiro estágio na melhoria de processo é a Engenharia de Valor, ou seja, a tentativa de redesenhar o produto mantendo a qualidade e a funcionalidade, mas reduzindo custos. O segundo estágio é a busca pela melhoria da fabricação do produto por meio da avaliação e seleção de tecnologias, ferramentas e procedimentos de fabricação (BORNIA, 1995).

Excesso de Estoque - Conforme Liker (2006, p. 48), é o excesso do inventário de matériaprima, de estoque em processo ou de produtos acabados, causando lead times mais longos, obsolescência, produtos danificados, custos de transporte e de armazenagem e atrasos. $\mathrm{O}$ estoque extraordinário pode ocultar problemas, como desbalanceamento de produção, entregas atrasadas de fornecedores, defeitos, equipamentos em conserto e longo tempo de setup (preparação). O Sistema Toyota de Produção considera os estoques como a origem de todos os problemas (SHINGO 1996b). Ohno (1997) afirma que o estoque em excesso é o maior desperdício de todos, já que determina a necessidade de muitos recursos como, por exemplo, um depósito, pessoas para realizar a manutenção, equipamentos de movimentação etc. O estoque em excesso causa falta de informações, dificulta a manutenção e a armazenagem (SHINGO, 1996b). Além disso, o estoque gera custos financeiros para sua manutenção, custos pela obsolescência dos produtos e custos de oportunidade de mercado em relação à concorrência que tiver menor lead time (BORNIA, 1995).

Movimentos Desnecessários - Segundo Liker (2006, p. 48) é qualquer movimento inútil que os funcionários têm que fazer durante o trabalho, tais como procurar, pegar ou empilhar peças, ferramentas, caminhar etc. Os desperdícios nos movimentos correspondem às ações consideradas inúteis ao processo e que são realizadas em linhas fabricação e máquinas. 
Defeitos - é a produção de peças defeituosas ou correção. Consertar ou re-trabalhar, descartar ou substituir a produção e inspecionar significam perdas de manuseio, tempo e esforço. Bornia (1995) considera que a minimização desta perda depende da confiabilidade do processo e da rápida detecção e solução de problemas. Shingo (1996a) afirma que esta perda pode ser eliminada por meio da inspeção para prevenir defeitos, e observa que as inspeções devem ser feitas, de modo que, quando defeitos ocorrem, medidas sejam tomadas para impedir a recorrência. Por outro lado, a inspeção realizada no final, que distingue produtos defeituosos de não-defeituosos, não tem efeito na redução das não-conformidades (SHINGO, 1996a).

Desperdício da criatividade dos funcionários - Segundo Liker (2006, p. 48), é a perda de tempo, ideias, habilidades, melhorias e oportunidades de aprendizagem por não envolver ou ouvir os seus funcionários. Conforme este autor, os termos japoneses que tratam sobre perdas são: a) Muda - nenhuma agregação de valor - Inclui os oito tipos de perdas mencionados anteriormente e contempla atividades supérfluas que aumentam lead times, causam movimentos extras para obter ferramentas ou peças, criam excesso de inventários / estoques ou resultam em alguma forma de espera; b) Muri - sobrecarga de pessoas ou de equipamentos - Significa colocar uma máquina ou uma pessoa, além de seus limites naturais, que pode resultar em problemas de segurança e qualidade e de equipamentos causando interrupções e defeitos; c) Mura - desnivelamento da produção - significa que será necessário ter a mão o equipamento, os materiais e as pessoas para o mais alto nível de produção, mesmo se as exigências normais forem muito menores. Para minimizar ou eliminar as perdas, uma ferramenta que pode ser utilizada é o Custeio Kaizen.

\subsection{Custeio Kaizen}

Custeio Kaizen é o processo de melhoramento contínuo aplicado na redução de custos durante a fabricação no ciclo de vida de um produto. De acordo com Cogan (1999), este custeio apresenta diversas características em comum: a) o foco é informar e motivar a redução do custo do processo, não o de obter custos de produtos mais apurados; b) a responsabilidade pela redução dos custos é do time, não uma responsabilidade individual, e c) os times de trabalho são responsáveis pela geração de ideias que visam a alcançar metas de redução de custos; tendo, inclusive, autoridade para fazer investimentos de pequena escala, desde que os mesmos terão retorno na correspondente redução de custos.

No contexto empresarial, o Custeio Kaizen envolve manter os níveis correntes de custo para os produtos e trabalhar sistematicamente para reduzir os custos aos valores desejados (MONDEN, 1999). Tem como objetivo o constante melhoramento do processo crítico, de tal forma que os custos possam ser continuamente reduzidos nas linhas de produtos que são maduras, altamente sensíveis a preço e não receptivas à inovação do produto (COGAN, 1999). De acordo com Sakurai 
(1997), o Custeio Kaizen envolve atividade de redução de custos para cada produto e atividades de redução do custo de cada período, que podem contemplar as reduções de perdas e desperdícios.

A inovação nos meios produtivos tem se tornado a base para o alcance desse novo paradigma, gerando maior competitividade estratégica em mercados globais (PRAJOGO et. al., 2007). Voss (1995) denomina este novo paradigma da manufatura como best practices (melhores práticas), que se baseiam no conceito de manufatura de classe mundial, porém abrangendo também outras áreas da empresa que contribuem para o aumento da competitividade, além da manufatura. Os vários padrões de estratégia de manufatura possuem vantagens e desvantagens, e o desejável seria a utilização integrada de diferentes padrões. É importante que os resultados da estratégia de manufatura sejam monitorados por índices de desempenho, visando a uma realimentação e à melhoria contínua (VOSS, 1995).

\subsection{Cinco S e VSM - Value Stream Mapping}

Os cinco S nasceu na década de 50, no Japão, onde a necessidade de re-organização do país pós-guerra era enorme. Os cinco S é considerado o primeiro e o principal passo para iniciar um programa da gestão da qualidade. Segundo Ohno (1997), o criador desta ferramenta foi Kaoru Ishikawa, que na década de 50 fundou a JUSE, (Japonese Union of Scientists and Engineers) responsável em promover a qualidade no Japão. Esta ferramenta foi implementada no (TPS) na Toyota como ponto de partida durante o processo de melhoria (SHINGO, 1996a).

A metodologia tem como principal objetivo mudar comportamentos e aprimorar atitudes, trocar informações entre funcionários e/ou áreas, contribuindo para uma administração mais participativa e de maior responsabilidade de todos com as condições de trabalho da empresa. Os 5 S's são baseados em cinco palavras japonesas: Seiri (Senso de Utilização), Seiton (Senso de Organização), Seiso (Senso de Limpeza), Seiketsu (Senso de Conservação) e Shitsuke (Senso de autodisciplina):

- Senso de Utilização: separar e manter no local de trabalho somente os materiais, máquinas e equipamentos necessários, descartando ou eliminando os desnecessários;

- Senso de Organização: definir a forma correta e o local adequado para a guarda de materiais, máquinas e equipamentos, tornando seu acesso rápido e fácil;

- Senso de Limpeza: eliminar a sujeira de materiais, máquinas e equipamentos do local de trabalho, atacando as fontes do problema;

- Senso de Conservação: garantir a continuidade das condições físicas e da saúde no local de trabalho, e

- Senso de Autodisciplina: cumprir os procedimentos e as normas mantendo o hábito naturalmente. 
VSM (Value Stream Mapping), em português, Mapeamento do Fluxo de Valor (MFV) é uma ferramenta desenvolvida pelo Operations Management Consulting Division (OMCD) da Toyota Motor Company, divisão organizada por Ohno (1997), originalmente, para implementar o Sistema Toyota de Produção (STP) nos fornecedores da Toyota. A ferramenta sintetiza os princípios do STP, ajudando a visualizar como está o processo em relação a esses princípios e auxilia a sua implementação (GHINATO, 1996). Apesar de a ferramenta ter sido desenvolvida na Toyota na década de 80, era desconhecida do público fora da Toyota até os anos 90 quando foi difundida por Rother \& Shook (2003), a pedido de Womack (WOMACK, 2006).

Por outro lado, é descrita por Liker (2006) como o décimo segundo princípio do Modelo Toyota em seu livro. É uma ferramenta que, assim como as outras da Produção Enxuta, concentrase mais nas questões relativas à redução do lead time (tempo de ciclo) dos sistemas. O tempo de ciclo parece ser a principal e, às vezes, a única dimensão considerada neste tipo de ferramenta. $\mathrm{O}$ objetivo em desenhar o mapa é identificar cada passo do processo que cria o valor desejado do ponto de vista do cliente. Especificamente, procura-se saber se cada passo do processo é valioso, capaz, adequado e flexível, no foco customização do processo (WOMACK, 2006).

\subsection{Cinco Porquês - 5W1H}

Diante da ocorrência de um problema, o Sistema Toyota de Produção sugere a utilização de um método que consiste em questionar cinco vezes "por que" e uma vez "como". Na visão de Shingo (1996a), as causas dos problemas são encontradas quando se pergunta "por que" cinco vezes ou mais, respondendo as questões do método 5W1H: "quem" (sujeito da produção), "o quê" (objetos da produção), “onde” (espaço), “quando" (tempo), "por que” (a causa para cada uma das perguntas acima) e "como" (métodos). Esta sistemática pode e deve ser utilizada na análise do processo, ou seja, as perguntas devem ser realizadas em cada etapa do processo (processamento, inspeção, transporte e espera).

\subsection{Diagrama de Causa e Efeito}

O Diagrama de Causa e Efeito, também conhecido como Diagrama de Espinha de Peixe ou Diagrama de Ishikawa, foi desenvolvido por Kaoru Ishikawa na Universidade de Tokyo em 1943 (SLACK et al., 2007). É um método de identificação de causas de perdas. Para cada problema (efeito) é possível estabelecer diferentes categorias principais de causas, porém as mais comuns são conhecidas como 6M: Mão-de-Obra (ou pessoas), Materiais (ou componentes), Máquinas (ou equipamentos); Métodos; Meio Ambiente e Medição. 


\subsection{PDCA}

Segundo Deming (1990), a qualidade define-se em função de quem a avalia, dando origem a dois conceitos: o interno e o externo. O conceito interno de qualidade, elaborado sob a ótica do produtor, refere-se à visão da mesma como o atendimento aos padrões internos definidos pela organização. Já o conceito externo de qualidade, relacionado ao ponto de vista do consumidor, assume que esta é determinada pela percepção do cliente, relacionando-se com a satisfação desejada. Para obter qualidade, é importante implementar o ciclo PDCA.

PDCA é uma sigla em inglês: Plan, Do, Check e Act; em português: Planejar, Fazer, Monitorar/Verificar e Agir. Conforme França e Freitas (1998, p. 99), o Ciclo PDCA representa a forma prática de concatenar as ações que levam a conquista da qualidade. E trabalhado em quatro quadrantes, conforme a seguir: Planejamento (Plan) - Toda ação deve ser planejada de maneira participativa; Execução (Do) - Executar as tarefas como foram vistas no plano e fazer a coleta de dados para verificação; Verificação (Check) - A partir dos dados coletados junto aos clientes, comparar esses dados com o exigido no plano, e Ações corretivas (Action) - As ações corretivas são conduzidas quando algum problema é localizado durante a fase de verificação. Na sequencia, serão tratados os aspectos metodológicos.

\section{Aspectos Metodológicos}

Devido ao assunto ser relativamente recente e estar em fase de estruturação e sistematização de conhecimentos, nesta pesquisa de caráter exploratório, optou-se em analisar apenas um caso, atentando-se para um estudo minucioso e aprofundado. Martins (2006, p.11) comenta que o estudo de caso, como estratégia de pesquisa, irá orientar na "busca de explicações e interpretações convincentes para situações que envolvam fenômenos sociais complexos, e a construção de uma teoria explicativa do caso, que possibilite condições para se fazerem inferências analíticas sobre proposições constatadas no estudo e outros conhecimentos encontrados".

Na opinião de Yin (2005, p.32), para justificar a escolha de um estudo de caso único, existem alguns fundamentos básicos, e este método é viável, já que esta pesquisa gera revelações de ordem científica, com pouca literatura existente. Os procedimentos de coleta de dados iniciaram-se em março de 2011 e duraram até meados de junho de 2011. Nesse período, foram feitas observação direta e participante, análise documental e entrevistas com os gestores da área produtiva. Como limitação da pesquisa, pode-se considerar que o estudo de caso único desenvolvido neste trabalho, apesar da profundidade do estudo, tal como comenta Yin (2005), pode impossibilitar a generalização dos resultados, pois o estudo não reflete o que ocorre em todas as indústrias do segmento ou em outros segmentos. 


\section{Estudo de Caso em Empresa de Autopeças}

Neste trabalho foi investigado como a metodologia da Manufatura Enxuta é aplicada em uma célula produtiva de empresa de autopeças, multinacional italiana, que fabrica sistemas e componentes para veículos automotores. A empresa não autorizou a divulgação de seu nome, e por isso será chamada de Empresa XPTO. Com 50 mil empregados diretos e faturamento anual em torno de $\mathrm{R} \$ 24$ bilhões, necessita de redução em seu preço de venda, devido à pressão das empresas concorrentes chinesas, que estão atuando e dominando o mercado.

Hajime Yamashina (2000) propôs uma metodologia de World Class Manufacturing (WCM) para a identificação e priorização de perdas que foi aplicada pela Empresa XPTO. Essa metodologia gera mudanças que facilitam a vida dos colaboradores e melhoram os resultados da empresa, bem como reúne as melhores práticas da produção industrial, visando à eliminação de desperdícios de qualquer espécie (de energia, de materiais e de esforço humano envolvido), melhorando a qualidade e reduzindo custo de transformação e prazo de entrega. Os resultados são maior flexibilidade produtiva, maior segurança, ergonomia e agilidade para o trabalhador, além de maior qualidade final dos produtos.

A metodologia de Yamashina (2000), implementada na empresa analisada, possui 10 pilares técnicos: segurança, desdobramento de custos, atividades autônomas, logística, meio ambiente, melhoria focada, manutenção planejada, gestão preventiva de equipamentos, desenvolvimento de pessoas e qualidade. Os pilares desta metodologia envolvem:

a) Segurança: melhoria do ambiente de trabalho e eliminação de condições de acidentes;

b) Desdobramento de Custos (Cost Deployment): identificar e combater as causas de perdas e desperdícios no sistema produtivo e logístico;

c) Atividades Autônomas: melhorar o clima de trabalho e facilitar as atividades, eliminando perdas e aumentando a produtividade;

d) Logística: produzir um fluxo eficiente, alinhar as variáveis envolvidas no processo e reduzir o estoque e a possibilidade de danos aos produtos;

e) Meio Ambiente: usar corretamente os recursos naturais e materiais disponíveis na fábrica;

f) Melhoria Focada (Focused Improvement): atacar as perdas mais importantes do sistema produtivo, aplicar técnicas, instrumentos e métodos específicos para solucionar problemas de dificuldade crescente em relação à complexidade das causas;

g) Manutenção Planejada (PM): reduzir avarias, aumentar eficiência das máquinas, reduzir custo de manutenção;

h) Gestão Preventiva de Equipamentos (EEM): ter equipamentos confiáveis, de fácil manutenção, diminuir o custo de vida dos equipamentos; 
i) Desenvolvimento de Pessoas: tratar da essência do sucesso do Programa WCM, e

j) Qualidade: assegurar produtos que garantem a máxima satisfação dos clientes.

Dentro dos pilares da WCM, estabelecem-se uma série de diretrizes como normas de padronização de produtos, de relação com fornecedores, disposição de materiais na fábrica, busca de nível zero de acidentes de trabalhos, eliminação de desperdícios, entre outras diretrizes; iniciando as atividades pelo pilar de desdobramento de custos, até chegar em qual a maior perda e como esta perda será atacada prioritariamente.

Os tipos de perdas relacionadas às máquinas utilizam os parâmetros deste indicador para medir os impactos das perdas na eficiência de todo o equipamento. As perdas relacionadas às máquinas que impactam em toda a eficiência do equipamento são: por quebra do equipamento; por troca (perda causada pela parada da máquina por troca de produto/molde devido ao plano de produção); por troca de material (perda causada pela parada da máquina devido ao consumo do material); por início/fim do equipamento (período de tempo no qual a linha deve ser preparada para o início/fim de produção e, portanto não produz no nível padrão); por pequenas paradas e espera do equipamento (bloqueio dos sensores).

Não são quebras, mas pequenos problemas que podem causar muitas paradas e comprometer a eficiência do equipamento); por tempo de ciclo diminuindo (considerando que o tempo de ciclo do equipamento é superior ao teórico de projeto); por equipamento inativo, planejado como parada de produção devido à falta de material na máquina (ex: falta de material direto, de mão-de-obra ou de energia elétrica); por equipamento não utilizado (por parada programada, domingos, feriados, turnos não utilizados etc.); por defeitos (considerando que o equipamento não produz peças qualitativamente aceitáveis), e por retrabalhos (re-ciclos).

As perdas relacionadas à mão-de-obra podem ser agrupadas em 5 grandes perdas: 1) Perdas de gestão; 2) Perdas nos movimentos operativos (Operating Motion Losses): NVAA (Not Value Added Activities); 3) Insaturação (perdas devido à diferença entre a cadência utilizada na linha e o tempo de ciclo da operação esperado); 4) Perdas por falta de automação, e 5) Perdas de mão de obra por defeitos de qualidade (Defect Quality Losses). As perdas derivadas de materiais são reagrupadas em três grandes perdas: 1) Perdas na utilização de materiais diretos e de consumo (por utilização de materiais ou componentes com defeitos qualitativos, por refugo de material na entrada, por refugo de produto ou semi-pronto, por utilização superior a norma, por start up); 2) Perda na utilização de energia elétrica para o start up, sobrecarga, perdas de temperatura, perda de ar/vapor por dispersão, e 3) Perdas sobre substituição de manutenção (devido ao consumo de peças de reposição e materiais de manutenção). 
No que diz respeito ao percurso de implementação, a primeira etapa consiste na formação e esclarecimento da equipe de trabalho. As atividades propostas nesta etapa são: (i) realizar reunião com funcionários envolvidos nas etapas do processo de produção e com a diretoria, e (ii) explicar a metodologia proposta pelo programa, montar a Matriz A listando quais as perdas relacionadas com mão de obra, materiais, equipamentos, as células e classificar o nível de perda qualitativamente. O Cost Deployment utiliza 7 passos para identificar, mensurar, atacar e avaliar o resultado com a eliminação de perdas e desperdícios no processo.

A lógica do percurso de realização é a seguinte:

Passo 1: A partir do custo total de transformação da fábrica e das análises da sua estrutura composição, estabelecem-se os objetivos de redução dos custos:

Figura 2: Custo de Transformação

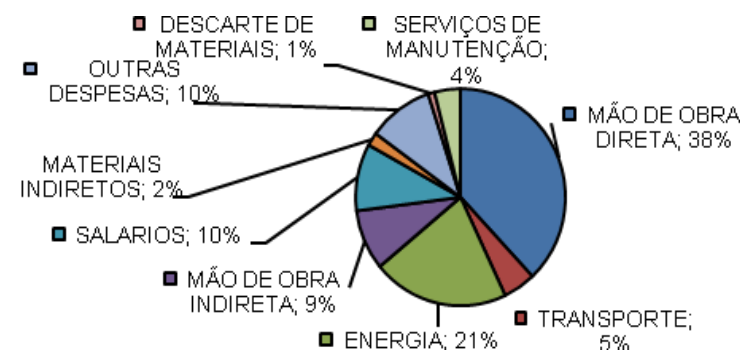

Fonte: Dados da Pesquisa (2011)

O custo de transformação para processo/unidade operativa, evidenciado na Figura 2, é o custo total de produção da empresa, retirando a depreciação, os materiais diretos e os impostos.

Passo 2: Identificam-se as perdas e os desperdícios, de modo qualitativo, alocando-os nos processos em que são incorridos (matriz $\mathrm{A}$ - perdas / processos):

Figura 3: Matriz A

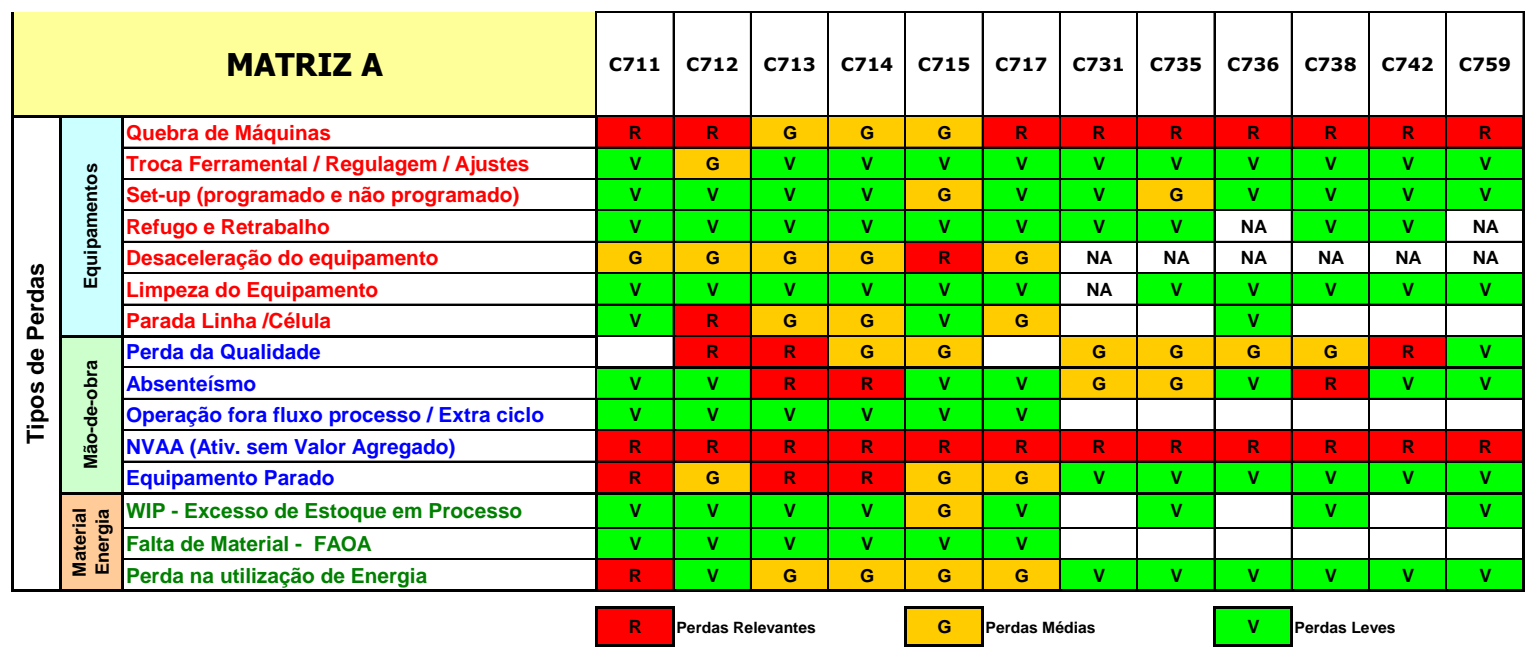

Fonte: Dados da Pesquisa (2011) 
Passo 3: A matriz A identifica onde estão as perdas no processo, classifica as perdas em elevada (vermelho), significativa (amarelo) e modesta (verde) pelo conhecimento da equipe. Por sua vez, na Matriz B, a seguir, identifica-se a correlação entre perda causal e todas as suas perdas resultantes:

Figura 4: Matriz B

\begin{tabular}{|c|c|c|c|}
\hline \multirow{15}{*}{$\begin{array}{l}0 \\
\mathbb{0} \\
0 \\
0 \\
0 \\
0 \\
0 \\
0 \\
0 \\
0 \\
0 \\
0\end{array}$} & \multirow{7}{*}{ 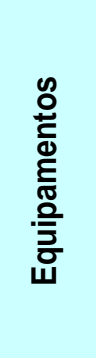 } & CAUSAL & Quebra de Máquinas \\
\hline & & CAUSAL /RESULTANTE & Troca Ferramental / Regulagem / Ajustes \\
\hline & & CAUSAL /RESULTANTE & Set-up (programado e não programado) \\
\hline & & RESULTANTE & Refugo e Retrabalho \\
\hline & & RESULTANTE & Desaceleração do equipamento \\
\hline & & RESULTANTE & Limpeza do Equipamento \\
\hline & & RESULTANTE & Parada Linha /Célula \\
\hline & \multirow{5}{*}{ 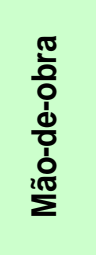 } & CAUSAL & Perda da Qualidade \\
\hline & & CAUSAL & Absenteísmo \\
\hline & & RESULTANTE & Operação fora fluxo processo / Extra ciclo \\
\hline & & CAUSAL & NVAA (Ativ. sem Valor Agregado) \\
\hline & & RESULTANTE & Equipamento Parado \\
\hline & \multirow{3}{*}{ 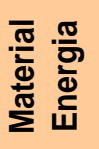 } & RESULTANTE & WIP - Excesso de Estoque em Processo \\
\hline & & CAUSAL /RESULTANTE & Falta de Material - FAOA \\
\hline & & CAUSAL & Perda na utilização de Energia \\
\hline
\end{tabular}

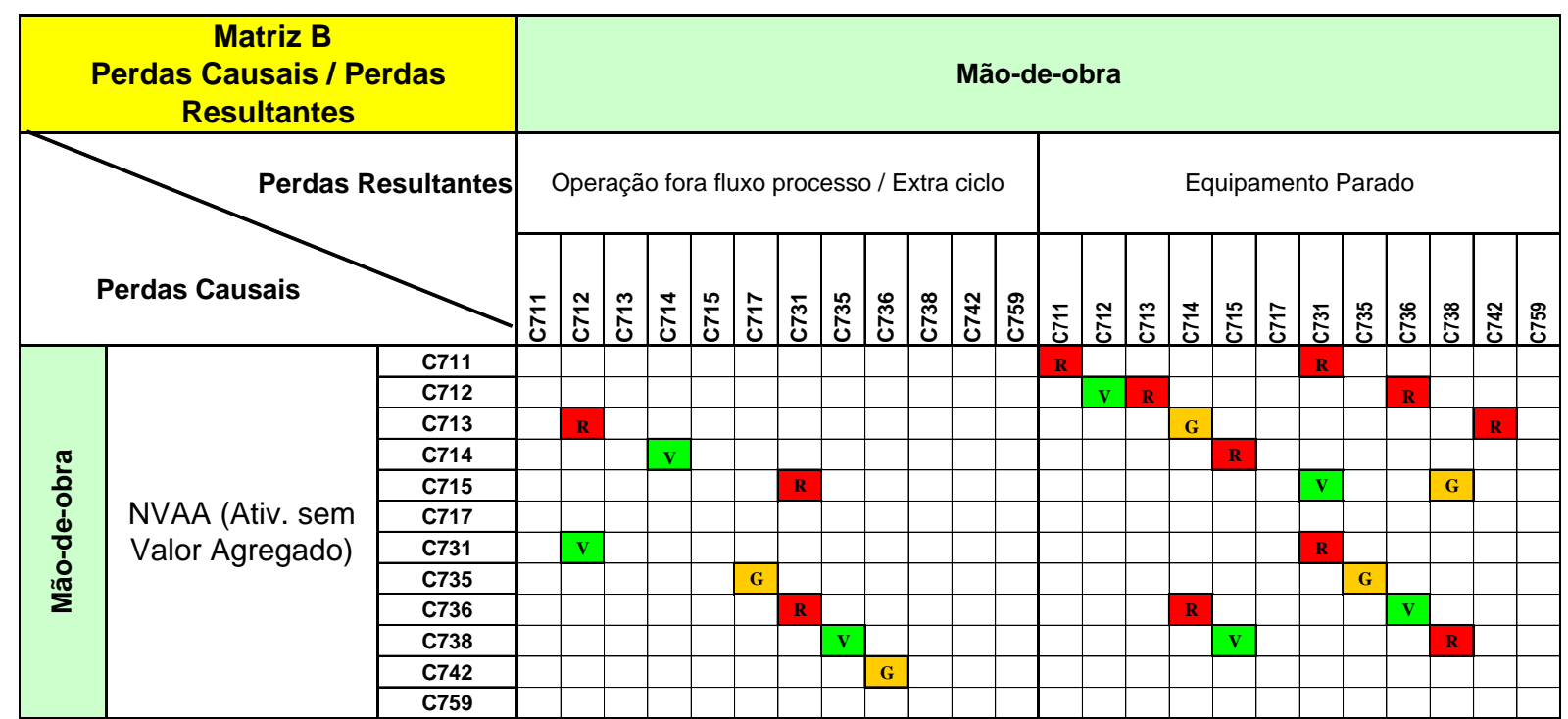

Fonte: Dados da Pesquisa (2011)

Para cada perda inserida na Matriz A, é necessário fazer uma distinção: causal ou resultante, que constam na Matriz B. Do ponto de vista da facilidade de ataque, uma perda resultante não é atacável, se não relacionada à que pode ser encontrada em outros processos / sub-processos diversos daqueles no qual se evidenciam as perdas resultantes. É importante analisar todo o processo, 
incluindo para cada perda causal de processo todas as perdas resultantes incorridas nos processos relacionados.

No exemplo a seguir, observa-se como uma perda causal de quebra originada em um processo pode gerar perdas resultantes nos processos seguintes. Por exemplo, parada forçada (que pode gerar os defeitos), perdas por falta de descarga, perdas por materiais indiretos e perda de energia. No processo anterior, verifica-se uma perda por espera quantificável em termos de custo de trabalho direto. Em todo o sistema, verifica-se uma perda de energia e uma perda de material direto, relacionadas aos defeitos produzidos.

Passo 4: Neste passo, evidenciado pela Matriz C, a seguir, transformam-se as dimensões das perdas e dos desperdícios identificados nas causas-raiz em custos; destacando, inclusive, as atividades sem valor agregado (NVAA):

Figura 5: Matriz C

\begin{tabular}{|l|l|l|l|l|l|l|l|}
\hline \multicolumn{9}{|c|}{ Matriz C } \\
$\begin{array}{l}\text { Estrutura do Custo } \\
\text { de Transformação }\end{array}$ \\
\hline
\end{tabular}

Fonte: Dados da Pesquisa (2011)

A Matriz C traduz os parâmetros físicos em custos (a partir da estrutura dos custos da fabrica, coletando as tarifas dos custos da mão-de-obra - tarifa horária da mão-de-obra direta, indireta e externa, dos custos de energia - força eletromotriz, iluminação, ar, água - custos de materiais materiais direto dos fornecedores e de outras fábricas, materiais indiretos de outros custos), tem a finalidade de identificar a perda mais crítica e onde ela está. Esta matriz produz um conjunto de dados a ser analisados por meio da estratificação, em diversos modos, para fornecer informações 
relacionadas ao tipo e ao valor das perdas geradas, a localização das perdas, a relação entre os custos de transformação e a estrutura dos custos das perdas.

Figura 6: Estratificação - Matriz C

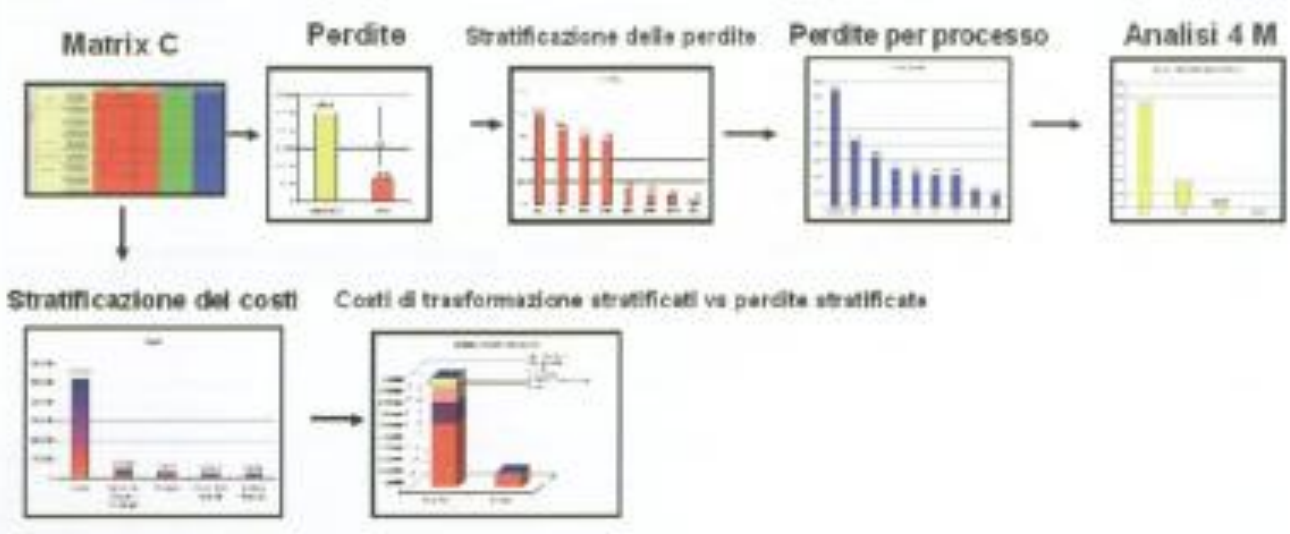

Fonte: Dados da Pesquisa (2011)

Passo 5: A estratificação é um instrumento que permite de analisar os dados disponíveis explodindo até o último nível possível por meio do Diagrama de Pareto $(80 \%$ dos custos concentram-se em $20 \%$ dos itens). Selecionam-se os métodos para eliminar as causas-raiz das perdas e dos desperdícios e estabelecem-se as prioridades (Matriz D - perdas/métodos):

Figura 7: Matriz C

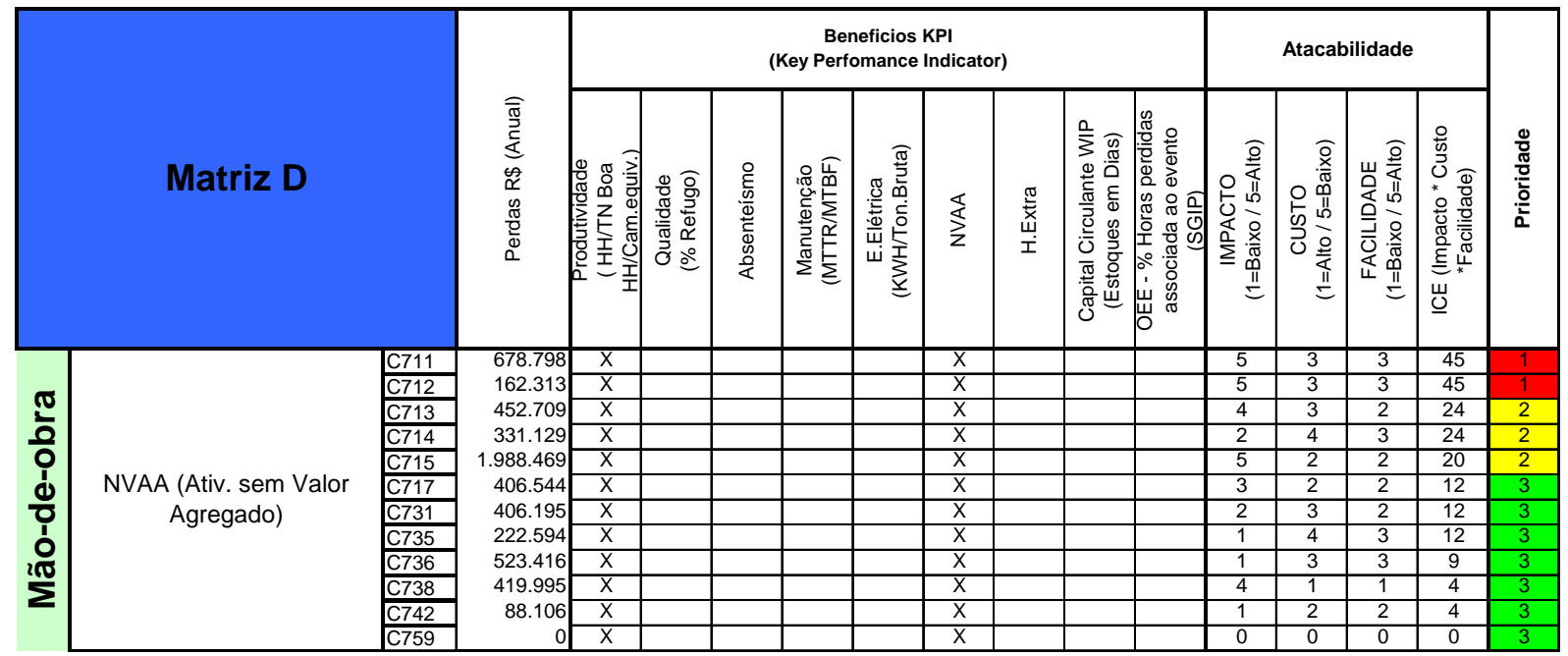

Fonte: Dados da Pesquisa (2011)

Na Matriz D são definidos os Indicadores-Chave de Desempenho - KPI’s da fábrica, e é estabelecida a prioridade de ações corretivas para evitar as perdas por meio do método ICF que envolve avaliar o Impacto, o Custo e a Facilidade de ocorrência das perdas causais mais importantes identificadas na Matriz C. O Impacto exprime com um ranking de 1 a 5, o valor econômico da perda identificada. O Custo exprime com um ranking de um valor mínimo a um valor máximo, o 
valor econômico dos custos a serem sustentados para a melhoria. A Facilidade exprime com um ranking de 1 a 5, o nível de facilidade a ser afrontada a perda (tempos e recursos). Na sequencia, a fórmula que contém a lógica do ICF:

ICF = I x C x F exprime qualitativamente com um ranking de 1 a 125 o nível de atacabilidade da perda.

Passo 6: Estimam-se os custos de implementação dos projetos para a eliminação das causas e as vantagens, em termos de redução dos custos, que são derivados (Matriz E - Custo/benefício). Na matriz E, a seguir, é feito um balanço econômico entre custo de implementação do novo método e o benefício derivado da redução das perdas, sendo possível optar por qual melhoria iniciar. As economias são, por definição, estimadas em base à estrutura de custo da fábrica; a tarifa e as condições produtivas de referência; mas requerem um processo de aprovação pela Administração. Após as melhorias escolhidas como prioridade de custo/benefício, um grupo multidisciplinar é formado para atacar a perda, utilizando o sistema kaizen.

Figura 8: Matriz E

\begin{tabular}{|c|c|c|c|c|c|c|c|c|c|c|c|c|}
\hline \multicolumn{13}{|c|}{ MATRIZ E } \\
\hline \multicolumn{4}{|c|}{ Vallores em R\$ / Ano } & \multicolumn{9}{|c|}{ Projetos } \\
\hline & \multirow{2}{*}{\multicolumn{2}{|c|}{ Gestão de Projetos }} & & Desciç̧āo & \multicolumn{5}{|c|}{ Viabidade } & \multicolumn{3}{|c|}{ Gestāo } \\
\hline & & & $\underset{0}{0}$ & Título &  & 总 & 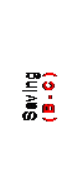 & $\frac{0}{m}$ & 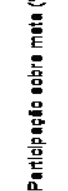 & 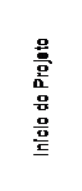 &  & \\
\hline \multirow{18}{*}{ 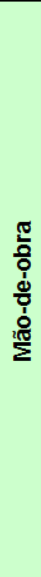 } & \multirow{18}{*}{$\begin{array}{l}\text { NVAA (Ativ. sem Valor } \\
\text { Agregado) }\end{array}$} & c711 & 419.995 & $\begin{array}{l}\text { Vabirizaçäo do carregamento de 100X de } \\
\text { sucata dos }\end{array}$ & 240.000 & 300.000 & 60.000 & 1,25 & 1,986 & 05No899 & 17/01/10 & PLAN \\
\hline & & c712 & 406.544 & Projeto Inovacãao .................... & .480. & 2900 & 2420 & 6,04 & $0,008 \%$ & 010909. & 3011/09. & CHECK \\
\hline & & c713 & $\begin{array}{ll}88.106 \\
\end{array}$ & Projeto Inovacão & 55 & 700 & 645 & 12,73 & $0,02 \%$ & 0109409 & 3011/09 & CHECK \\
\hline & & c714 & 331.129 & Projeto Inovacão........... & 100. & 3.000 & 2900 & 30.00 & $0,10 \%$ & 010999 & 3011/49. & CHECK. \\
\hline & & \multirow{2}{*}{ C715 } & \multirow[t]{2}{*}{222.594} & Projeto Inovacão & 305 & 2243 & 1993 & 7,35 & $0,06 x$ & 010949 & MU11/09 & CHECK \\
\hline & & & & Saluracâao de mâo-de-obra & 18.060 & 129.000 & 110.940 & 7,14 & $3,67 \%$ & 01084T & MN01/10 & PLAN \\
\hline & & \multirow{2}{*}{ c717 } & \multirow[t]{2}{*}{162.313} & Projeto Inovação & 479 & 2.998 & 2519 & 6,25 & $0,08 \%$ & 010990 & 3011/f09 & DO \\
\hline & & & & Saluraça de mäo-de-obra & 14.190 & 129.000 & 114.810 & 9,09 & 3,806 & $010 \mathrm{aNO}$ & 01709A9 & ACT \\
\hline & & \multirow{3}{*}{ c731 } & \multirow[t]{3}{*}{678.798} & Projeto Inovacão & 10.814 & 45555 & 34.741 & 4,21 & $1,15 \%$ & 010909 & 3M11/49 & CHECK \\
\hline & & & & Saluracâa de mâo-de-obra & 98.000 & 174.000 & 76.000 & 1,78 & $251 \%$ & 010909 & 30102/10 & Do \\
\hline & & & & Dispositivo pi Medir Aluwa do Flange & 23.128 & 43.000 & 19.872 & 1,86 & $0,66 \%$ & 0806709 & $07 / 12 \mathrm{Nag}$ & CHECK \\
\hline & & \multirow{3}{*}{ c735 } & \multirow[t]{3}{*}{523.416} & Saluraçäo de mâo-de-obra & 4.401 & 68396 & 63.995 & 15,54 & $2,12 \times$ & 2506709 & 25A9R/9 & ACT \\
\hline & & & & Produci Mercure Mariner na oéluda Thrssen. & 1.200 & 112400 & 111.200 & 93.67 & 3,606 & 014210 & 2010210 & ACT \\
\hline & & & & Saluracāo de mäo-de-obra & 8.000 & 86.000 & 78.000 & 10,75 & $2,58 \%$ & $30 / 1109$ & 3001/10 & PLAN \\
\hline & & \multirow{3}{*}{ C742 } & \multirow{3}{*}{ 1989.469 } & Projeto Inovação & 575 & 10.720 & 10.145 & 18,64 & $0,34 \%$ & 0109799 & 3011/49 & CHECK \\
\hline & & & & Cracáa de Palet para Embatugem & 300 & 5000 & 4700 & 16,67 & $0.16 \%$ & 2009909 & 21/N9A9 & CHECK \\
\hline & & & & Saluracáo de mâo-de-obra & 454.500 & 1.075 .000 & 620.500 & 2,37 & $20,51 \%$ & 30/1109 & 3M06/10 & PLAN \\
\hline & & C759 & 158.000 & Projeto Inovação & 80 & 120 & 40 & 1,50 & $0,00 x$ & & & CHECK \\
\hline
\end{tabular}

Fonte: Dados da Pesquisa (2011)

Passo 7: Definem-se os planos de melhoria, coletam-se os resultados e realiza-se o monitoramento. 


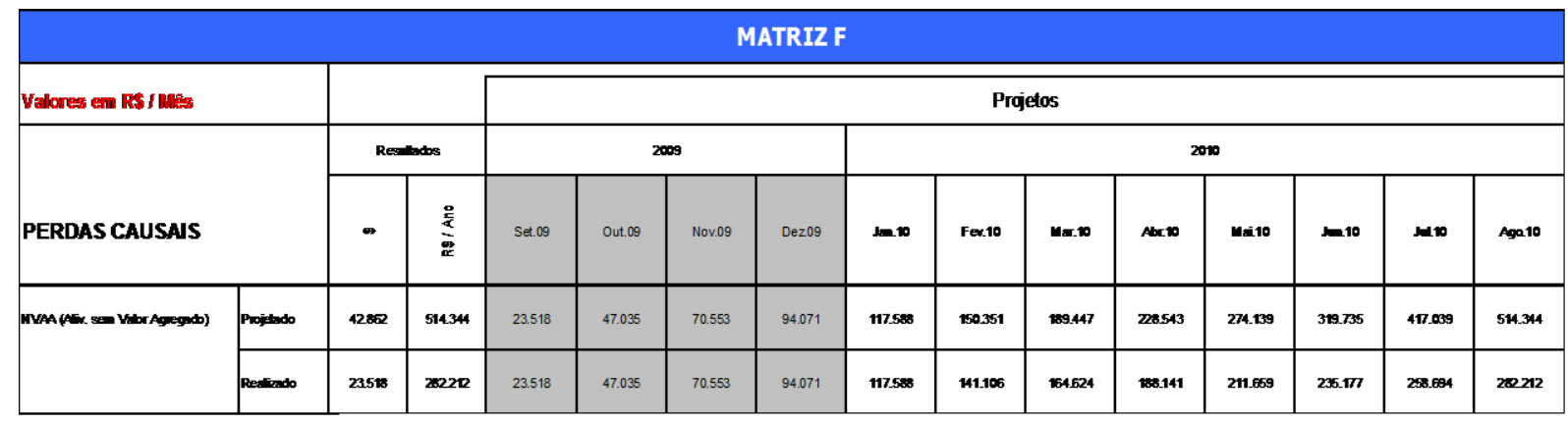

Fonte: Dados da Pesquisa

A Matriz F gerencia as melhorias com e eliminação ou redução das perdas em cada área, mensurando em termos financeiros qual será a redução no custo de transformação. Após a conclusão do passo 7, as Atividades de Cost Deployment devem recomeçar do passo 5, levando em consideração a Matriz A dos custos e das perdas, com a finalidade de selecionar outras perda evidenciadas, e que não foram atacadas por falta de recursos; mas que podem ser atacadas com outros projetos que podem utilizar os recursos liberados após o resultado de eficiência do ciclo de projetos encerrados.

A duração sugerida para cada projeto é de três meses, e se os projetos são complexos, requerendo um tempo superior aos 3 meses, sugere-se dividi-los em sub-projetos com objetivos intermediários, de duração menor. Uma vez concluídos os dois ciclos de execução dos projetos (aproximadamente em 6 meses), e após terem sido validados os projetos concluídos, o Cost Deployment deve ser repetido a partir do passo 1, visando a identificar novas perdas e desperdícios e novas relações entre as perdas que no Cost Deployment anterior não tinham sido evidenciadas. Realiza-se, dessa forma, um processo de refinamento na capacidade de verificar e identificar novas perdas e desperdícios.

A partir dos passos do Cost Deployment, foi identificado na matriz que a maior perda na fábrica são as atividades que não agregam valor - NVAA. Com o estudo dos tempos de cada célula da fábrica, conseguiu-se identificar que apenas $30 \%$ das atividades de mão-de-obra direta agregam valor ao produto e $70 \%$ das atividades não agregam valor. A partir desse estudo houve um incentivo da Empresa XPTO para projetos de melhoria com redução das atividades que não agregam valor, tais como: movimentação, espera, transporte, defeitos, desorganização do posto de trabalho, conforme fluxo da peça, as máquinas, os operários e o material estavam desorganizados, causando assim atividades que não agregam valor ao produto, e não possuem um fluxo contínuo.

Após a finalização da Matriz D com a priorização de onde atacar primeiro pelo método ICF, a estratificação mostrou que a célula XY deveria ser a primeira a formar uma equipe e atacar a sua perda com mão-de-obra. Essa célula possuía três operadores por turno, a saturação de obra de 49\%, 
área ocupada de $100 \mathrm{~m} 2$, o fluxo da peça de $17,47 \mathrm{~m}$, a produção da célula de 70 peças / hora e tempo ciclo de 4,28 h/h / 100 peças.

Montou-se uma equipe multidisciplinar e realizou-se um plano de ação para melhorar a perda com espera e movimentação na célula XY. De acordo com a metodologia empregada, utilizou-se o método kaizen, as ferramentas da qualidade $5 \mathrm{~W} 1 \mathrm{H}$, os $5 \mathrm{~S}$ 's, diagrama de Causa e Efeito, PDCA e a matriz de perdas para identificação de qual seria a primeira célula a ser atacada. Utilizou-se a ferramenta de 5S's para limpar e organizar o posto de trabalho, mudança de máquinas e planejou-se o novo fluxo do processo. Houve a mudança do layout, além de mudança de processo, máquinas, transporte e entrega e posição dos materiais. Após a mudança, foi medido, novamente, o tempo ciclo e o tempo de atividades que não agregam valor, por meio do estudo dos tempos. Conforme se observa na Figura 10, a seguir, após a mudança no layout, o processo torna-se contínuo:

Figura 10 - Alterações no Layout
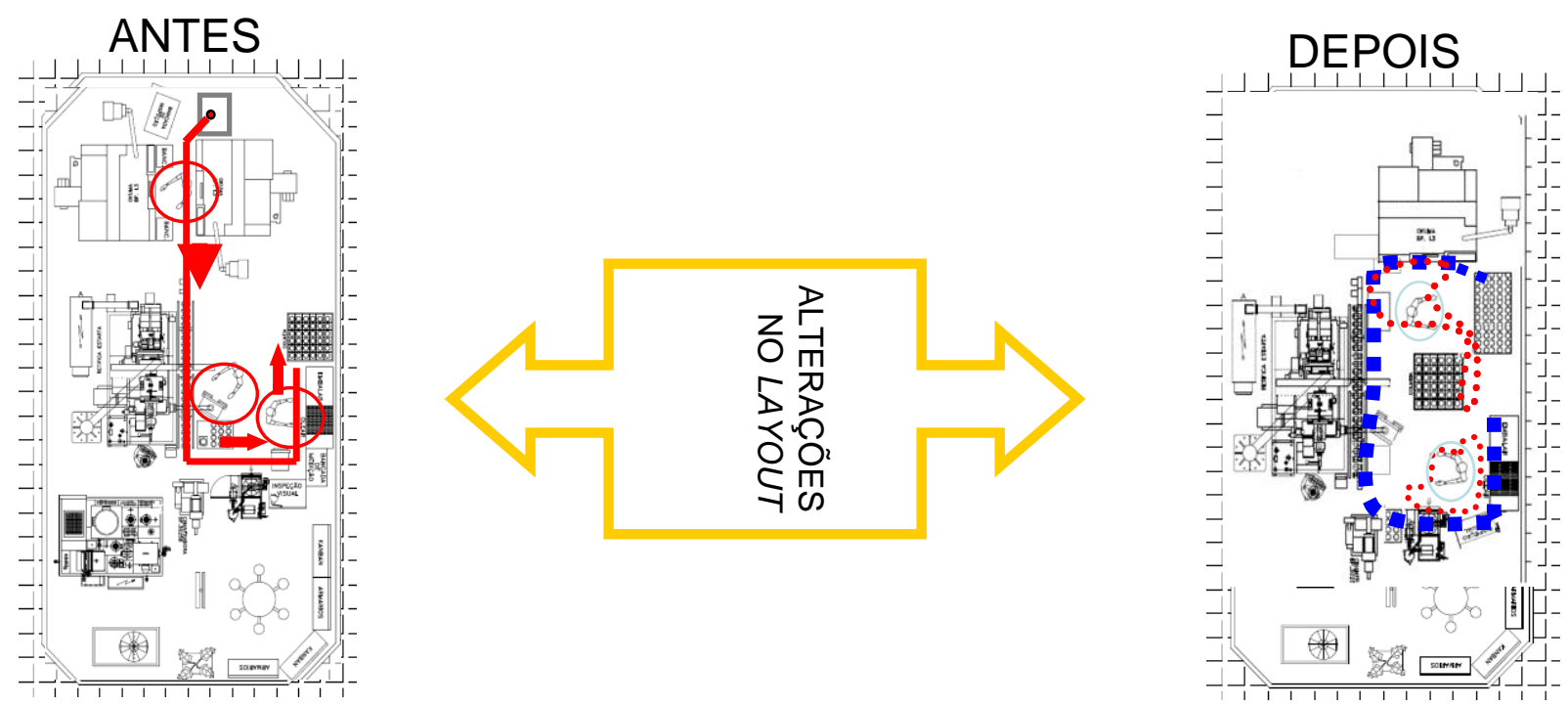

Fonte: Dados da Pesquisa (2011)

Após a mudança, a célula XY passou a ter dois operadores por turno; a saturação de mão-deobra foi para $73 \%$; área ocupada de $95 \mathrm{~m} 2$; o fluxo da peça de $13,80 \mathrm{~m}$; a produção da célula de 70 peças / hora e tempo ciclo de 2,85 h/h / 100 peças. Concluiu-se que, após a mudança, a produtividade aumentou, o tempo ciclo diminuiu, reduziram-se dois operários por turno, ou seja, seis operários; reduzindo, assim o custo com mão-de-obra direta. A entrega de materiais tornou-se mais rápida e a célula ficou com menos movimentações e atividades que não agregam valor, assim como o transporte ficou mais rápido.

Como resultados econômico-financeiros do projeto, foram gerados $\mathrm{R} \$ 50.634,00$ de reduções de custos, além de proporcionar o balanceamento da linha; o aumento produtividade; a 
redução de NVAA (transporte e movimentação), a motivação dos operadores por meio da participação nas sugestões de melhorias (Projetos Kaizen) e a organização e limpeza do posto de trabalho. O custo total do projeto foi de $\mathrm{R} \$ \mathrm{R} \$ 6.359,00$, devido às mudanças de máquinas e a compra de um carro pantográfico; obtendo-se uma economia total no projeto (saving) de R\$ $44.275,00$.

Com isso, a empresa irá tornar-se mais competitiva no mercado, uma vez que as empresas concorrentes chinesas possuem um preço de venda menor, e a cada dia estão ganhando mais participação no mercado. Com as melhorias e redução de perdas e desperdícios, a empresa pode diminuir seu preço de venda, melhorar a qualidade dos produtos, melhorar as condições de seus funcionários, aumentar a segurança e diminuir o tempo de entrega, cumprindo com os prazos negociados com os clientes.

Após o estudo da metodologia de Yamashina (2000), aplicada na empresa XPTO, constatouse que, por meio da ação de melhoria contínua em uma célula, houve redução no custo, aumento da produtividade e redução do tempo ciclo. Se adotado o mesmo método para as demais células fabris, a empresa terá o seu objetivo de redução de preços de venda alcançado.

\section{Conclusões}

O objetivo do trabalho foi atingido, sendo que no Estudo de caso desenvolvido, foram analisadas as matrizes do Cost Deployment, inicialmente, com a mensuração do custo de transformação. Posteriormente, seguiram-se os passos com a Matriz A, em que se identificaram as principais perdas e indicaram-se as células de produção, separando as perdas resultantes das perdas causais na matriz B. Na matriz C, identificaram-se os custos das perdas no processo; a priorização de projetos por meio do método ICF que foi feito na Matriz D; na Matriz E, utilizou-se para o controle de projetos e a Matriz $\mathrm{F}$ foi desenvolvida para mensurar qual foi a redução no custo de transformação com os projetos de melhoria contínua.

$\mathrm{Na}$ Matriz D foi identificado que a célula a ser atacada primeiramente é a célula XY. Montou-se, então, uma equipe multidisciplinar para iniciar o projeto de melhorias para atacar a perda com atividades que não agregam valor, em que foram aplicadas as ferramentas de PDCA, 5W1H e Gráficos de Ishikawa para identificação da causa-raiz. Após análises, a equipe montou um novo fluxo de peças. Concluiu-se que, após a mudança de layout a produtividade aumentou, o tempo ciclo diminuiu, houve a redução no custo de mão-de-obra direta de um operador por turno; reduzindo assim o custo de transformação. A entrega de materiais tornou-se mais rápida e a célula ficou com menos movimentações e atividades que não agregam valor, assim como o transporte ficou mais rápido. 
Após outras mudanças, a empresa vai tornar-se mais competitiva no mercado, uma vez que as empresas concorrentes chinesas possuem um preço de venda menor, e a cada dia está ganhando mais participação no mercado. Com as melhorias e redução de perdas e desperdícios, a empresa pode diminuir seu preço de venda, melhorar a qualidade dos produtos e as condições de seus funcionários, ampliar a segurança e diminuir o tempo de entrega, cumprindo com os prazos negociados com os clientes.

Diante disso, a empresa continuará com o programa de identificação e ataque às perdas, proporcionando incentivos para a continuação da participação dos funcionários em projetos de melhoria continua. Sugere-se que estudos futuros apresentem uma aplicação completa dos procedimentos metodológicos propostos neste trabalho, em empresas de outros segmentos, que não apenas o de autopeças.

\begin{abstract}
The aim of this paper is to investigate, through case study, the loss on operations for movement in a work cell, which does not add value, and seek alternatives to minimize these losses by using tools to achieve cost reductions. Developed research on auto parts company, according to the methodology of the World Class Manufacturing of Yamashina (2000), focusing on losses reduction, wastes and therefore costs. We used the method kaizen, quality tools $5 \mathrm{~W} 1 \mathrm{H}$, the 5S's, VSM, Cause and Effect Diagram, Matrix and the PDCA cycle losses. There was a change in layout and process change, machinery, transport, delivery and management of materials. As a result, increased productivity, decreased cycle time, were two workers per shift decreased, reducing the cost of direct labor. There were economic and financial benefits of $\mathrm{R} \$ 50,634.00$, and provide a balanced line, increasing productivity, reducing non-value added activities (shipping and handling), the motivation of operators by means of suggestions for improvements and the organization and cleaning of the workplace. The total project cost was $\mathrm{R} \$ 6,359.00$, yielding a total savings of $\mathrm{R} \$ 44,275.00$. With the improvements and reduction of losses and wastes, the company can lower its selling price, making it more competitive in the market, and improve product quality and conditions of its employees, reduce delivery time and complying with terms negotiated with customers.
\end{abstract}

Key-words: kaizen; lean manufacturing; losses; productivity; wastes.

\title{
Referências
}

ÅHLSTRÖM, P.; KARLSSON, C. Change processes towards lean production: The role of the management accounting system. International Journal of Operations \& Production Management, v. 16, no. 11, p. 42-56, 1996.

cress ref

BORNIA, A. C. Mensuração das perdas dos processos produtivos: uma abordagem metodológica de controle interno. Tese (Doutorado em Engenharia de Produção), Universidade Federal de Santa Catarina, 1995.

BRINSON, J. A. Contabilidade por atividades: uma abordagem de custeio baseado em atividades. São Paulo: Atlas, 1996.

CLARK, K. Competing through manufacturing and the new manufacturing paradigm: is manufacturing strategy passé?

Production and Operations Management. HBS Press, Boston, MA. v. 5, n.1, p. 42-68, 1996.

COGAN, S. Custos e preços: formação e análise. São Paulo: Pioneira, 1999.

DRUCKER, Peter F. Managing for the Future. New York: Dutton, 1992. 
DEMING, W. Edwards. Qualidade: a revolução da administração. Rio de Janeiro: Marques Saraiva, 1990.

FRANÇA, F. F.; FREITAS, S. G. Manual da qualidade em projetos de comunicação. São Paulo: Pioneira Thompson, 1997.

GHINATO, P. Sistema Toyota de Produção: mais do que simplesmente just-in-time. 1ed. Caxias do Sul: EDUSC, 1996.

HAYES, R. H.; PISANO, G. P. Manufacturing Strategy: at the intersection of two paradigm shifts. Production and Operations Management. HBS Press, Boston, MA. v. 5, n.1, p. 25-41, 1996.

HAYES, R.H.; WHEELWRIGHT, S.C. Restoring Our Competitive Edge: Competing Through Manufacturing. John Wiley, New York. 1984.

IMAI, M. Kaizen: a estratégia para o sucesso competitivo. 5. ed. São Paulo: Imam, 1994.

LIKER, J. K. Modelo Toyota: os 14 Príncipios de gestão do maior fabricante do mundo. Porto Alegre: 2006.

MARTINS, G. de A. Estudo de Caso: Uma estratégia de pesquisa. São Paulo: Atlas, 2006.

MONDEN, Y. Sistemas de redução de custos: custo-alvo e custo kaizen. Porto Alegre: Bookman, 1999.

NAKAGAWA, M. Gestão estratégica de custos: conceitos, sistemas e implementação. São Paulo: Atlas, 1993.

OHNO, T. O Sistema Toyota de Produção: além da produção em larga escala. Porto Alegre: Bookman, 1997.

PRAJOGO, D. I.; LAOSIRIHONGTHONG, T.; SOHAL, A.; BOON-ITT, S. Manufacturing strategies and innovation performance in newly industrialized countries. Industrial Management \& Data Systems. v. 107, n.1, p. 52-68, 2007. cross ref

ROBLES Jr., A. Custos da qualidade: uma estratégia para competição global. 2a . Ed. São Paulo: Atlas, 2003.

ROTHER, M.; SHOOK, J. Aprendendo a enxergar: mapeando o fluxo de valor para agregar valor e eliminar o desperdício. São Paulo: Lean Institute Brasil, 1999.

SAKURAI, M. Gerenciamento integrado de custos. São Paulo: Atlas, 1997.

SHAH, R.; WARD, P. T. Lean manufacturing: context, practice bundles, and performance. Journal of Operations Management. v. 335, p. 1-21, 2002.

SHINGO, S. O sistema Toyota de Produção do ponto de vista da engenharia de produção. Porto Alegre: Bookman, 1996a.

SHINGO, S. Sistemas de produção com estoque zero: O sistema Shingo para melhorias contínuas. Porto Alegre: Bookman, 1996b.

SCHONBERGER, R. J. World Class Manufacturing; The lessons on simplicity Applied. The Free Press, New York, 1986.

SLACK, N.; CHAMBERS, S.; JOHNSTON, R. Administração da Produção. São Paulo: Atlas, 2007.

SOLOMON, J. M.; FULLERTON, R. Accounting for World-Class Operations Fort Wayne, Indiana: WCM Associates, 2007.

VOSS, A.C. Alternative paradigms for manufacturing strategy. International Journal of Operations \& Production Management, v.15, n.4, p.5-16, 1995.

cressef

WOMACK, J. P.; JONES, D. T.; ROOS, D. A máquina que mudou o mundo. 7a. Ed. Rio de Janeiro: Campus, 2004.

YAMASHINA, H. Challenge to World Class Manufacturing. International Journal of Quality of Reliability Management. v. 17, no. 2, p. 132-143, 2000.

cress ref 
YIN, R. K. Estudo de Caso: Planejamento e Método. 3ª Ed. Porto Alegre: Bookman, 2005.

\section{Dados dos autores:}

Nome completo: Ana Cristina De Faria

Filiação institucional: Universidade Municipal de São Caetano do Sul

Departamento: Programa de Pós-Graduação em Administração

Função ou cargo ocupado: Professora em Tempo Integral

Endereço completo:

Rua Juvenal Parada, 281, ap. 72 - Mooca - São Paulo - SP - CEP: 03167-060

Telefones para contato: (11) 4239.3354 / 9912.6431

E-mail: anacfaria@uol.com.br

\section{Nome completo: Vanessa Simões Vieira}

Filiação institucional: Universidade Municipal de São Caetano do Sul

Departamento: Pós-Graduação Lato Sensu - MBA em Controladoria e Contabilidade Estratégica

Função ou cargo ocupado: Especialista em Controladoria e Contabilidade Estratégica

Endereço completo: Rua Santo Antonio, 50 - Centro - São Caetano do Sul - SP - CEP: 09521-160

- Pós Lato Sensu

Telefones para contato: (11) 4239.3354

E-mail:vanessavieira@mmcb.com.br

Nome completo: Luiz Celso Peretti

Filiação institucional: Universidade Municipal de São Caetano do Sul

Departamento: Pós-Graduação Stricto Sensu - Mestrado em Administração

Função ou cargo ocupado: Mestrando em Administração

Endereço completo: Alameda São Caetano, 204 - Bairro Jardim Santo Andre - SP - CEP: 09070210 - Telefones para contato: (11) 44322762

E-mail:luizcelsoperetti@gmail.com

Enviado em: 21/05/2012

Aprovado em: $12 / 08 / 2012$ 